\title{
Micellar solubilization of fatty acids in aqueous media containing bile salts and phospholipids
}

\author{
By A. SMITH AND A. K. LOUGH \\ Rowett Research Institute, Bucksburn, Aberdeen $A B 2{ }_{9} S B$
}

(Received 7 April 1975 - Accepted 8 May 1975)

\begin{abstract}
I. The solubility of fatty acids in aqueous media containing bile salts alone and in admixture with either lecithin (phosphatidylcholine) or phosphatidylethanolamine was determined.

2. Over the $\mathrm{pH}$ range $2 \cdot 0-7 \cdot 4$, the order of fatty acid solubility in aqueous solutions containing bile salts was linoleic $>$ oleic $>$ elaidic $>$ palmitic $>$ stearic. The solubility of each fatty acid increased as the $\mathrm{pH}$ of the micellar solution increased.

3. Addition of lecithin to aqueous solutions of bile salts greatly increased the solubility of palmitic acid and stearic acid.

4. In the presence of bile salts and lecithin, the solubility of oleic acid and elaidic acid decreased with increasing $\mathrm{pH}$ of the micellar solution, indicating a competitive effect between the fatty acid anions and lecithin. The solubility of linoleic acid increased linearly with lecithin concentration.

5. Phosphatidylethanolamine as an additive to bile salts increased the solubility of both saturated and unsaturated fatty acids in the $\mathrm{pH}$ range $2 \cdot 0-7 \% 4$. The effectiveness of phosphatidylethanolamine as an amphiphile was similar to that of lecithin, although at $\mathrm{pH}_{3.0}$ fatty acid solubility was greater in the presence of phosphatidylethanolamine.

6. The significance of these findings is discussed in relation to the intestinal absorption of fatty acids in sheep.
\end{abstract}

In adult sheep given a normal diet, the digestion of lipids begins in the enlarged forestomach (reticulo-rumen) where micro-organisms hydrolyse glycerolipids and the resulting unesterified, long-chain fatty acids are hydrogenated (Garton, 1967). Thus, the lipids of post-rumen digesta are virtually free of monoglyceride and the fatty acids mainly comprise stearic and palmitic acids, together with a range of octadecenoic acids mostly of the trans-configuration; the digesta lipids also include structural components of micro-organisms of rumen origin. The lipid components of sheep duodenal digesta are predominantly associated with particulate matter (Scott \& Lough, 1971).

In the sheep, absorption of unesterified, long-chain fatty acids and the uptake and dissimilation of esterified fatty acids takes place in the jejunum (i.e. the proximal half of the small intestine), where the $\mathrm{pH}$ of the lumen contents varies from about 2.5 (proximal) to about 8.0 (distal). Absorption of fatty acid is most pronounced in the middle and lower jejunum, though it also occurs under the markedly acidic conditions of the upper jejunum (Lennox \& Garton, r968).

Palmitic acid and stearic acid and their sodium salts are virtually insoluble in water at physiological temperatures (John \& McBain, I948; McBain \& Sierichs, I948) and therefore some form of solubilization of these acids is a pre-requisite for their absorption in the sheep. Scott \& Lough (I97I) found that the addition of sheep gall-bladder bile to heat-inactivated duodenal digesta resulted in a transfer of unesterified fatty acids from association with the particulate matter of the digesta into micellar solution 
and they found that this transfer was due largely to the solubilizing action of bile salts acting together with biliary phospholipids.

A study was undertaken to determine the maximal solubility of the main fatty acids of sheep intestinal digesta and of elaidic acid in aqueous solutions of mixed bile salts either alone or in admixture with biliary lecithin (phosphatidylcholine) and phosphatidylethanolamine, at $\mathrm{pH}$ values and electrolyte concentrations similar to those which exist in the lumen of the small intestine of the sheep.

\section{EXPERI MENT AL}

\section{Materials}

${ }^{\mathrm{I}-}{ }^{14} \mathrm{C}$-labelled long-chain fatty acids and $\left[\mathrm{I}-{ }^{14} \mathrm{C}\right]$ stearyl alcohol were purchased

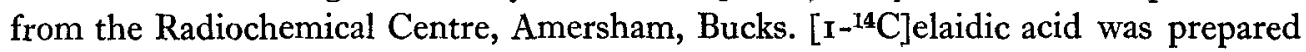
by the isomerization of $\left[\mathrm{I}^{14} \mathrm{C}\right]$ oleic acid (Freeman, I969). Unlabelled fatty acids were purchased either from Sigma Chemical Co. Ltd, London, or from Price's Chemicals Ltd, Wirral, Cheshire, and were at least $99 \%$ pure.

Mixed conjugated bile acids were isolated from sheep gall-bladder bile by the method of Smith, Anderson \& Lough (1973). Lecithin was isolated from the yolks of hens' eggs (Rhodes \& Lea, I957) or from sheep gall-bladder bile (Lennox, Lough \& Garton, I968); phosphatidylethanolamine was isolated from ox brain (Rouser, 1968). The isolated phosphatidylethanolamine contained about $300 \mathrm{mg}$ phosphatidylethanolamine/g.

\section{Methods}

Fatty acid analysis. The component fatty acids of the isolated phospholipids were analysed as their methyl esters by gas-liquid chromatography (Pye Series 104; Pye-Unicam Ltd, Cambridge) at $185^{\circ}$ using $1 \cdot 5 \mathrm{~m} \times 4 \mathrm{~mm}$ i.d. glass columns packed with $150 \mathrm{~g}$ polymerized ethylene glycol adipate (Supelco Inc., Bellefont, Pennsylvania, USA) or with $70 \mathrm{~g}$ Apiezon L (Shell Chemicals Ltd, London)/kg Celite 545 (80/100 mesh) (Shandon Scientific Co., London). Table I gives the fatty acid composition of lecithin isolated from hens' eggs and from sheep gall-bladder bile and of phosphatidylethanolamine prepared from ox brain.

Thin-layer chromatography. The homogeneity of the isolated phospholipids and bile salts was checked by thin-layer chromatography; the adsorbent used was Kieselgel G (E. Merck AG, Darmstadt, West Germany) and the solvents for the lipids, which were visualized using Zinzadze's reagent (Dittmer \& Lester, I964), were those recommended by Malins \& Mangold (1960). The appropriate solvents and spray reagents of Hofmann ( 1964 ) were used for the detection of the bile salts.

Separation of glycine-conjugated and taurine-conjugated bile acids. Glycine-conjugated and taurine-conjugated bile acids were separated by silicic-acid column chromatography, using increasing concentrations of methanol in chloroform as eluants. The bile salts were dissolved in a minimum (known) volume of methanol to which known volumes of chloroform were added until the point of incipient precipitation of the bile salts was reached. This point occurred at a ratio of $16: 84(\mathrm{v} / \mathrm{v})$ methanol- 
Table r. Component fatty acids (mg/g) of lecithin isolated from sheep gall-bladder bile and from hen' egg and of phosphatidylethanolamine prepared from ox brain*

\begin{tabular}{|c|c|c|c|}
\hline $\begin{array}{l}\text { Fatty } \\
\text { acid }\end{array}$ & $\begin{array}{l}\text { Sheep gall-bladder } \\
\text { bile lecithin }\end{array}$ & $\begin{array}{l}\text { Hens' egg } \\
\text { lecithin }\end{array}$ & $\begin{array}{l}\text { Ox brain } \\
\text { phosphatidylethanolamine }\end{array}$ \\
\hline $14: 0$ & 5 & - & - \\
\hline I 5:0 & 7 & - & 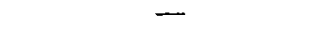 \\
\hline 16:0 & 254 & 347 & 55 \\
\hline I6: I & 68 & I9 & 12 \\
\hline $17: 0$ & 14 & - & - \\
\hline I8:0 & 122 & I30 & I62 \\
\hline I8: 1 & 297 & 322 & 291 \\
\hline $18: 2$ & 79 & 164 & - \\
\hline $18: 3$ & 65 & - & - \\
\hline $20: I$ & - & - & 78 \\
\hline $20: 4$ & 89 & I4 & 94 \\
\hline $22: 4$ & 一 & - & 78 \\
\hline $22: 6$ & - & 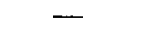 & 230 \\
\hline
\end{tabular}

chloroform. This solution was applied to a silicic-acid column (20 g adsorbent/g bile salts), which was eluted successively with solutions containing methanol-chloroform $(16: 84,18: 82$ and $20: 80, v / v)$ to elute the glycine-conjugates while the taurineconjugates were subsequently eluted with methanol-chloroform $(25: 75, \mathrm{v} / \mathrm{v})$ and finally with methanol. Analysis of the column eluants using thin-layer chromatography indicated that complete separation of the two species of bile salts had been obtained.

Determination of the solubility of long-chain fatty acids in aqueous solutions of bile salts alone or in admixture with phospholipids. ${ }_{\mathrm{I}}{ }^{14} \mathrm{C}$-labelled fatty acids and unlabelled fatty acids in chloroform were transferred to glass test-tubes and the solvent removed by evaporation in a stream of nitrogen; the final traces of solvent were removed under reduced pressure. Mixed bile salts, either alone or in admixture with phospholipid, in buffer solution at the appropriate $\mathrm{pH}$ value, were added and the total volume in the test-tube was made to $7.0 \mathrm{ml}$ with buffer solution. The buffer solution used in the solubility studies was of constant ionic strength $(0 \cdot 5 \mathrm{~mol} / \mathrm{l})$ over the $\mathrm{pH}$ range $2 \cdot 0-7 \cdot 4$ (Elving, Markowitz \& Rosenthal, I956).

The contents of the test-tubes were heated to about $75^{\circ}$ for I min, or until all the solid fatty acid had melted, and the suspension was transferred into $\mathrm{I}_{4} \mathrm{ml}$ capacity polycarbonate centrifuge tubes (Measuring and Scientific Equipment Ltd, Crawley, Sussex). The test-tubes were rinsed by the addition of $2 \mathrm{ml}$ buffer solution which was heated for $3 \circ$ s at $70^{\circ}$ and transferred to the polycarbonate tubes using a Pasteur pipette. During the transfer period the temperature of the solution in the centrifuge tubes was not allowed to go below $45^{\circ}$. The centrifuge tubes were sealed with stainless-steel cap assemblies and incubated at $37^{\circ}$ with shaking for $48 \mathrm{~h}$, by which time an equilibrium state was reached.

After incubation the centrifuge tubes were transferred to a centrifuge rotor head (MSE65 centrifuge; Measuring and Scientific Equipment Ltd), prewarmed at $37^{\circ}$, and were centrifuged at $80000 \mathrm{~g}$ for $\mathbf{2} \mathrm{h}$. The centrifuge tubes were withdrawn with 


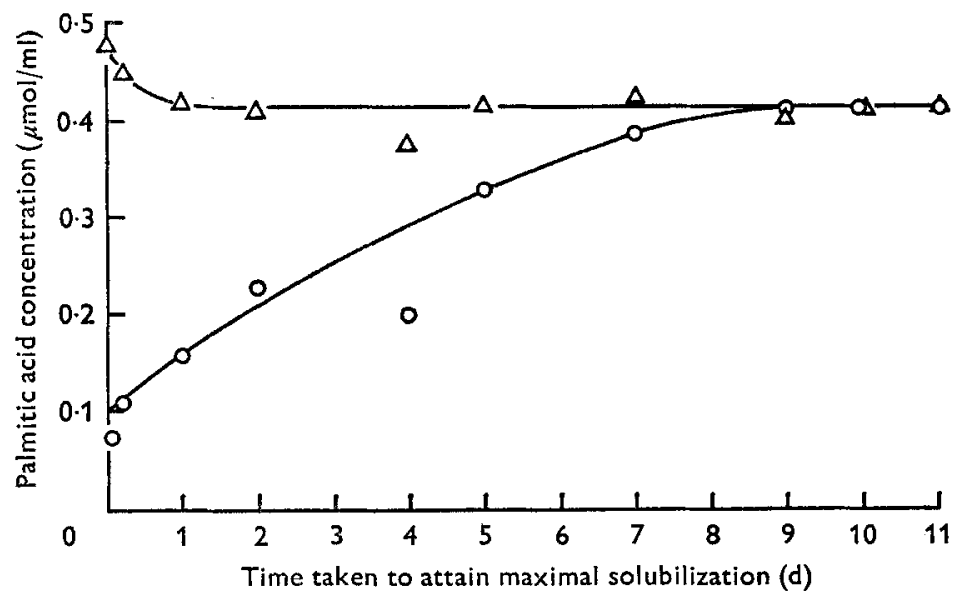

Fig. I. Rate of attainment of maximal solubilization of palmitic acid in aqueous solutions of ro mmol bile salts $/ 1$ at $\mathrm{pH} 4.0$ and $37^{\circ} . \triangle$, Fatty acid suspension heated to about $75^{\circ}$ for $\mathrm{r} \min$; $O$, fatty acid suspension not heated. For details of experimental procedure, see p. 79 .

the minimum of agitation to the layer of excess acid, and the grub-screws removed from the sealing-cap assemblies. Using a hypodermic syringe fitted with a stainlesssteel needle, about $5 \mathrm{ml}$ of the micellar phase were transferred to a test-tube held in a water bath at $37^{\circ}$. Samples ( $\mathrm{I} \mathrm{ml}$ ) of the micellar phase were mixed with $15 \mathrm{ml}$ scintillation fluid (4 g 2,5-diphenyloxazole/1 toluene-Triton X-100 (2:I, v/v)) and the amount of radioactivity was measured in a liquid scintillation spectrometer (Tricarb; Packard Instrument Co., Illinois, USA), using the 'channels ratio' method to correct for quenching (Hendler, 1964).

\section{RESULTS}

\section{Composition of mixed bile salts isolated from sheep gall-bladder bile}

The bile salt preparation contained about $75 \%$ taurine-conjugates and about $25 \%$ glycine-conjugates. Cholic acid was the predominant bile acid although small amounts $(<5 \%)$ of chenodeoxycholic acid and deoxycholic acid were also found.

\section{Rate of attainment of equilibrium of fatty acids in aqueous solutions of bile salts}

The rate of attainment of maximal solubilization of palmitic acid in an aqueous solution of ro mmol bile salts $/ 1$ at $\mathrm{pH} 4.0$ with and without heating is shown in Fig. r. With no initial heating, maximal solubility was not obtained until after about $9 \mathrm{~d}$, but heating the aqueous solution before incubation resulted in attainment of an equilibrium state within $48 \mathrm{~h}$. Furthermore, the solubility of fatty acids in aqueous solutions of bile salts with or without added phospholipid was not influenced by heating the mixture before it was incubated at $37^{\circ}$. 
Table 2. Effect of $p H$ on the saturation ratio (mol micellar solute:mol micellar bile salt) for long-chain fatty acids in aqueous solutions of bile salts at $37^{\circ *}$

\begin{tabular}{lllll} 
& \multicolumn{4}{c}{ pH } \\
\cline { 2 - 5 } Fatty acid & 2.0 & 4.0 & 6.0 & 7.4 \\
Palmitic & 0.03 & 0.04 & 0.18 & 0.41 \\
Stearic & 0.02 & 0.03 & 0.08 & 0.14 \\
Oleic & 0.11 & 0.16 & 0.51 & 0.98 \\
Elaidic & 0.10 & 0.11 & 0.30 & 0.49 \\
Linoleic & 0.18 & 0.21 & 0.64 & 1.09
\end{tabular}

* For details of experimental procedure, see p. 79 .

\section{Influence of $p H$ on the solubilization of long-chain fatty acids in aqueous solutions of bile salts}

Solubility curves were obtained for palmitic, stearic, oleic, elaidic and linoleic acids in aqueous solutions of bile salts over the $\mathrm{pH}$ range $2 \cdot 0-7 \cdot 4$ and from these the saturation ratio (mol micellar solute: mol micellar bile salt (Hartley, 1938; Hofmann, I963)) for each acid was calculated (Table 2). Mixed bile salt solutions were in the concentration range $0-40 \mathrm{mmol} / 1$.

The values given in Table 2 indicated that long-chain fatty acids, in particular palmitic, stearic and elaidic acids, were only sparingly soluble in aqueous solutions of bile salts under acidic conditions; their solubility increased with increasing $\mathrm{pH}$ of the micellar solution. Unsaturated fatty acids, e.g. oleic and linoleic acids, were readily soluble at $\mathrm{pH} 7.4$; about $\mathrm{I} \mathrm{mol}$ fatty acid $/ \mathrm{mol}$ bile salts is solubilized. Over the $\mathrm{pH}$ range $2 \cdot 0-7 \cdot 4$ the order of solubility of the fatty acids studied was linoleic $>$ oleic $>$ elaidic $>$ palmitic $>$ stearic.

\section{Influence of lecithin on the solubilization of long-chain fatty acids in aqueous solutions of bile salts}

In order to estimate the maximum solubility of fatty acids in a mixed micellar solution containing bile salts and lecithin, the bile salt concentration was kept constant at $10 \mathrm{mmol} / \mathrm{l}$ and the lecithin concentration was in the range $0-0.4 \mu \mathrm{mol} / \mathrm{ml}$.

The effectiveness of an amphiphile in increasing fatty acid solubility in aqueous solutions of bile salts may be expressed in terms of an amphiphilic index, derived from the linear part of the solubility curve, and defined as the ratio, increase in fatty acid solubility $(\mu \mathrm{mol})$ : amount of added amphiphile $(\mu \mathrm{mol})$ (Freeman, 1969).

Values for the amphiphilic indices of the fatty acids studied are given in Table 3. The results indicate that over the $\mathrm{pH}$ range $2 \cdot 0-7 \cdot 4$ lecithin, as an adjuvant to bile salts, greatly increased the solubility of palmitic and stearic acids. The uptake of these acids into micellar solution increased when the lecithin concentration and the $\mathrm{pH}$ were increased.

A number of single determinations were made at $\mathrm{pH}$ values intermediate to those given in Table 3 and it was found that the amphiphilic indices increased progressively from pH $2 \cdot 0$ to $7 \cdot 4$. 
Table 3. Effect of $p H$ on the amphiphilic index (ratio, increase in solubility $(\mu \mathrm{mol}): \mu \mathrm{mol}$ lecithin added (Freeman, 1969)) of fatty acids in solutions containing bile salts and lecithin at $37^{\circ *}$

\begin{tabular}{lllrr} 
& \multicolumn{4}{c}{$\mathrm{c}$} \\
Fatty acid & 2.0 & 4.0 & 6.0 & 7.4 \\
Palmitic & 0.54 & 0.56 & 0.81 & 1.09 \\
Stearic & 0.14 & 0.18 & 0.26 & 0.35 \\
Oleic & 6.82 & 0.40 & -6.36 & -9.71 \\
Elaidic & 1.29 & 0.44 & 0.22 & 0.00 \\
Linoleic & $8.90 \dagger$ & $10.75 \dagger$ & $14.50 \dagger$ & nd
\end{tabular}

nd, Not determined.

* For details of experimental procedure, see p. 79 .

+ Valid only up to a lecithin concentration of about $0.15-0.20 \mu \mathrm{mol} / \mathrm{ml}$ (see Fig. 2).

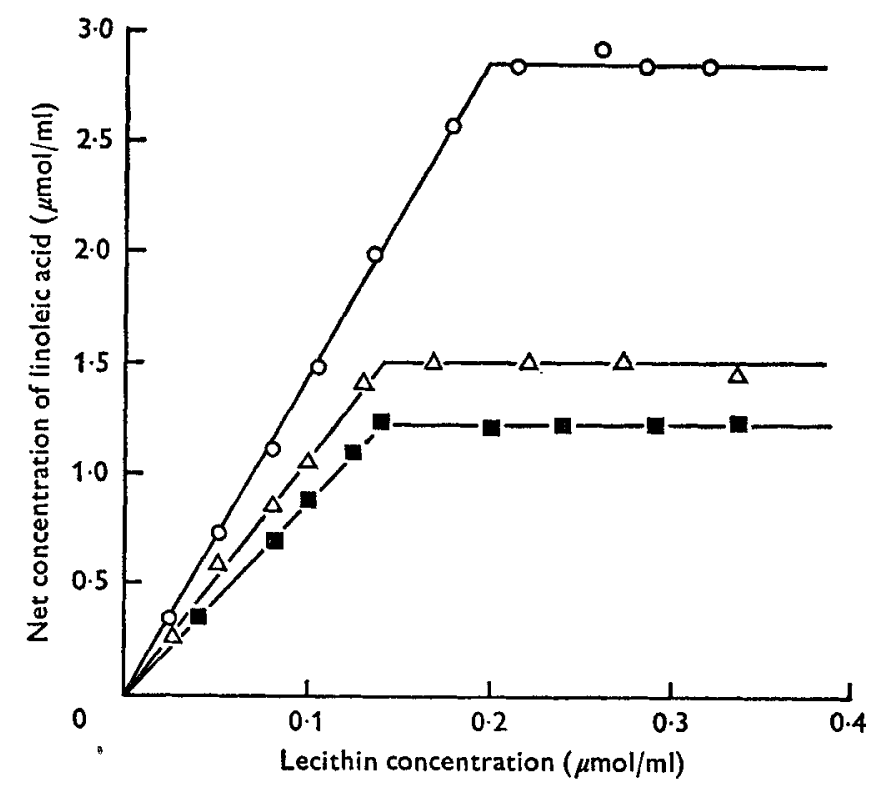

Fig. 2. Effect of added lecithin on the solubilization of linoleic acid in aqueous solutions of Io mmol bile salts $/ 1$ at $37^{\circ} . \mathrm{v}, \mathrm{pH} 2 \cdot 0 ; \triangle, \mathrm{pH} 4.0 ; 0, \mathrm{pH} 6.0$. For details of experimental procedure, see p. 79 .

In contrast, the solubility of monounsaturated fatty acids in solutions containing bile salts and lecithin decreased with increasing $\mathrm{pH}$; the effect was more marked with the $c i s$-isomer than with the trans-isomer. Thus, at $\mathrm{pH} 6.0$ and 7.4 the addition of lecithin resulted in a decrease in the amount of oleic acid incorporated into micellar solution whereas at $\mathrm{pH} 7.4$ lecithin was apparently without influence on the uptake of elaidic acid.

In Fig. 2, which shows the effect of added lecithin on linoleic acid solubility in bile salt solution, allowance was made for the solubility of fatty acid in bile salt solution alone, and thus the solubility curves start from a common point irrespective of the 


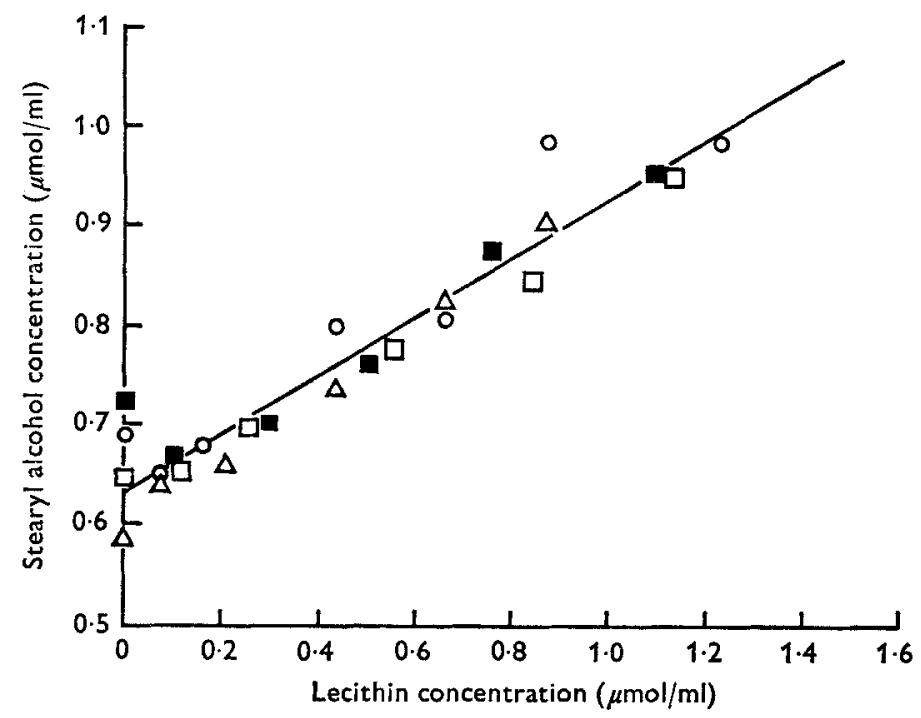

Fig. 3. Effect of added lecithin on the solubilization of stearyl alcohol in an aqueous solution of

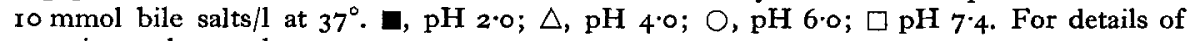
experimental procedure, see p. 79 .

$\mathrm{pH}$ value of the aqueous media. The results in Table 3 and Fig. 2 indicate that the solubility of linoleic acid increased linearly up to a lecithin concentration of $0.15-0.20$ $\mu \mathrm{mol} / \mathrm{ml}$, above which it remained constant.

Previous results (Table 2 ) indicated that the solubility of fatty acids in bile salt solution increased with increasing $\mathrm{pH}$ of the aqueous solution. To determine whether this finding was related to the contribution of fatty acid ionization, the solubility of a non-ionizable compound, stearyl alcohol, in bile salt-lecithin micellar solution over the $\mathrm{pH}$ range $2 \cdot 0-7 \cdot 4$ was studied. Results (Fig. 3 ) indicated that the solubility of this compound, unlike that of long-chain fatty acids, was not affected by the $\mathrm{pH}$ of the micellar solution.

An assessment of the influence of the component fatty acids of lecithin on fatty acid solubility in the presence of bile salts was made by a study of the solubility of stearic acid in bile salt solutions containing either egg lecithin or bile lecithin. Although there was a difference in fatty acid composition of the lecithins (Table 1 ), the solubility of stearic acid was the same in the presence of either amphiphile.

\section{Influerce of phosphatidylethanolamine on the solubilization of long-chain fatty acids in aqueous solutions of bile salts}

The solubility of fatty acids in bile salt-phosphatidylethanolamine micellar solutions within the $\mathrm{pH}$ range $2 \cdot 0-6 \cdot 0$ was estimated as described previously; the bile salt concentration was kept constant at ro $\mathrm{mmol} / \mathrm{l}$.

Amphiphilic indices were determined from the solubility curves of the fatty acids in bile salt solutions containing phosphatidylethanolamine. The values given in Table 4 indicate that the acid solubility was dependent on the $\mathrm{pH}$ of the micellar 
Table 4. Effect of $p H$ on the amphiphilic index (ratio, increase in solubility ( $\mu$ mol): $\mu \mathrm{mol}$ phosphatidylethanolamine added) of fatty acids in solutions containing bile salts and phosphatidylethanolamine at $37^{\circ *}$

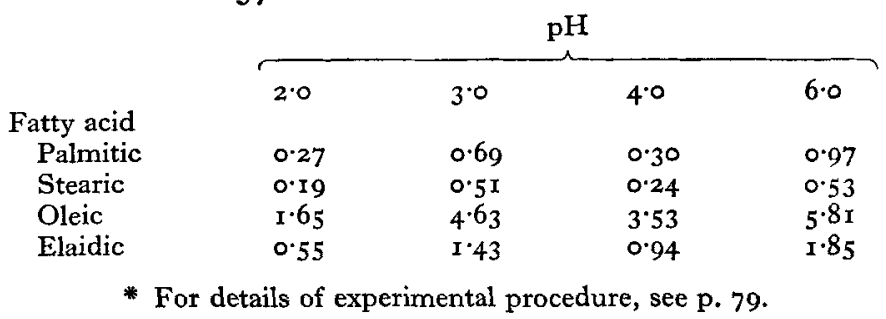

solution. However, at $\mathrm{pH} 3.0$ the amphiphilic indices for all the acids studied were higher than those at $\mathrm{pH}_{4}{ }^{\circ}$. Above $\mathrm{pH}_{4}^{\circ} \mathrm{O}$, in contrast to the solubility characteristics of monounsaturated acids in bile salt-lecithin micellar solutions, those in bile salt solutions containing phosphatidylethanolamine increased with increasing $\mathrm{pH}$ of the aqueous medium.

\section{DISCUSSION}

The results of the present study indicate that in aqueous media containing bile salts, fully protonated long-chain fatty acids are poorly solubilized. Of the acids studied, stearic acid was least soluble, with only one molecule of acid in association with about forty molecules of bile salts. Appreciably greater proportions of the ionized form of the acids were solubilized by bile salt solution, though even at $\mathrm{pH} 7 \cdot 4$ the saturation ratio for stearate was only $0^{\circ} \mathrm{I} 4$, whereas that for oleate and linoleate was unity. In accordance with the findings of other workers, the extent of solubilization of fatty acids in the presence of bile salts increased with decreasing chain length and with the number of double bonds (Savary, 1966; Freeman, 1969).

The addition of lecithin in physiological amounts of aqueous solutions of bile salts greatly increased the uptake of fatty acids into micellar solution. In particular, it was found that fully-protonated fatty acids were incorporated to give molecular ratios for fatty acid:lecithin which varied from $\mathrm{I}: 6$ for stearic acid to 9: I for linoleic acid.

As was found in experiments involving bile salts without the addition of phospholipid, palmitic, stearic and linoleic acids were taken into micellar solution to an increasing extent when the $\mathrm{pH}$ of the aqueous media was increased. This effect was probably caused by the change in ionization of the fatty acid: the extent to which stearyl alcohol was solubilized in the presence of bile salts and lecithin was not influenced by an increase in $\mathrm{pH}$ from $2 \cdot 0$ to $7 \cdot 4$.

Both oleic and elaidic acids were found to have anomalous behaviour in regard to the effect of increasing $\mathrm{pH}$ in the presence of bile salt and lecithin. Thus the solubilities of these acids decreased in a manner which suggested a competitive effect between the fatty acid anions and lecithin. Competition between additives has been reported by Hofmann \& Borgström (I962) who found that there was competitive solubilization between sodium oleate and mono-olein in sodium glycodeoxycholate solution at $\mathrm{pH} \mathrm{6.3.} \mathrm{The} \mathrm{explanation} \mathrm{for} \mathrm{this} \mathrm{phenomenon} \mathrm{is} \mathrm{not} \mathrm{readily} \mathrm{apparent.}$ 
The extent to which fatty acids were solubilized in the presence of bile salts with phosphatidylethanolamine as the amphiphile was similar to that in bile salt-lecithin solutions, except for anomalously high values for the uptake of fatty acids at $\mathrm{pH} 3 \cdot 0$ and for the absence of any competitive effect between phosphatidylethanolamine and octadecenoic acid at $\mathrm{pH} 6 \cdot 0$.

Because the preparation of phosphatidylethanolamine used in these studies contained a substantial proportion of the ether analogue, it is not possible to compare directly the effect of phosphatidylethanolamine with that of lecithin. Nevertheless, bile salt micelles containing phosphatidylethanolamine probably differ in some respects from those containing lecithin, since it is known that lecithin is zwitterionic over the $\mathrm{pH}$ range used in the solubilization studies, whereas phosphatidylethanolamine, which is zwitterionic in the region of $\mathrm{pH} 3^{\circ} \mathrm{O}$, would be expected to have a net negative charge at about $\mathrm{pH} 7 \cdot 4$ (Bangham, I968).

The bile salts used in the solubilization studies were isolated from sheep gallbladder bile and consisted of a mixture of taurine-conjugated acids and glycineconjugated acids in the approximate ratio $3: \mathrm{r}$. With regard to the $\mathrm{p} K_{a}$ values of bile acids conjugated with taurine or glycine (Hofmann \& Small, rg67), it is apparent that at $\mathrm{pH} 7 \cdot 4$ all the added bile salts are ionized and are available for micelle formation whereas at $\mathrm{pH} 2 \cdot 0$ only about one-third of the total bile salts, i.e. about half the taurine-conjugates, are ionized and form micelles. At $\mathrm{pH} 2 \cdot 0$, precipitation of the fully protonated bile acids is prevented by the presence of the taurine conjugates (Small, 1971).

As was mentioned earlier, long-chain unesterified fatty acids are the main lipid constituents of digesta entering the small intestine of sheep given normal diets. The fatty acids are associated with the particulate matter of digesta and, though the form of association is not known, there is evidence to suggest that the acids are fully protonated, are probably located on the surfaces of the solid phase, and are completely accessible to the solubilizing action of aqueous solutions of bile salts and lecithin (Scott \& Lough, 1971; Smith \& Lough, 1973). Though the present studies relate to conditions under which maximum solubilization was reached within $48 \mathrm{~h}$, the highly dispersed form of the fatty acids on the particulate matter of the digesta in vivo evidently results in a more rapid uptake of the acids into micellar solution in the intestinal lumen.

The presence in the intestinal lumen of bile secretion, with its complement of bile salts and lecithin, is of fundamental importance to the over-all process of lipid absorption in sheep, as indicated by the finding that diversion of bile secretion from the small intestine virtually stops the uptake of lipid from the lumen contents (Heath $\&$ Morris, 1963 ; Heath \& Hill, r 969 ; Leat \& Harrison, 1969). In addition, the results of experiments using sheep fitted with double re-entrant cannulas in the small intestine have indicated that, while uptake of long-chain, unesterified fatty acids from the intestinal lumen mostly occurs in the lower three-quarters of the jejunum, some absorption apparently takes place in the upper jejunum, where the lumen contents are markedly acidic and where lecithin is the predominant form of esterified fatty acid (Lennox \& Garton, 1968). 
It is therefore probably relevant that, as found in the present study, mixed micelles comprising lecithin and bile salts can solubilize long-chain fatty acids to an appreciable extent under the extreme conditions of acidity $(\sim \mathrm{pH} 2)$ that exist in the upper jejunal lumen of the sheep (Lennox \& Garton, I968).

Though the $\mathrm{pH}$ in the lumen of the middle and lower jejunum increases distally, thereby favouring the incorporation of fatty acids into mixed micelles with bile salts and lecithin, the amount of lecithin which is available for micelle formation in the intestinal lumen is continually decreasing as a result of the action of pancreatic phospholipases; the over-all influence of intact lecithin on fatty acid absorption in sheep is therefore difficult to assess. In this connexion, the results of experiments in which pancreatic secretion was diverted from the small intestine of sheep suggest a marked reduction in the absorption of unesterified fatty acid (Leat \& Harrison, 1969). The reduction in $\mathrm{pH}$ of the lumen contents which results from loss of the complement of pancreatic bicarbonate is likely to exert a profound effect on the uptake of fatty acids into micellar solution; thus, a reduction of about $\mathrm{r} \cdot 5 \mathrm{pH}$ units was found in the intestinal contents of sheep deprived of pancreatic and bile secretions (Leat \& Harrison, 1969). It has been found in the present study that in aqueous media containing bile salts and lecithin, a decrease in $\mathrm{pH}$, particularly in the region of the $\mathrm{p} K_{a}$ of the fatty acid, markedly reduces the extent to which fatty acids may be solubilized. In addition, the association of appreciable amounts of biliary lecithin with the particulate matter under the acidic conditions which exist in the upper jejunal lumen of normal sheep is likely to be increased when the buffering action of pancreatic bicarbonate is absent from the small intestine; the amount of lecithin readily available for micelle formation would thus be reduced.

Phosphatidylethanolamine of microbial and biliary origin (Kunsman, 1966; Lennox et al. 1968) is present in the lumen of the small intestine of the sheep. The results in Table 3 indicate that, as an additive to bile salts, phosphatidylethanolamine is at least as efficient as lecithin in promoting the solubilization of long-chain fatty acids. The increased solubility of fatty acids in bile salt-phosphatidylethanolamine micellar solutions at $\mathrm{pH} 3.0$ may be of importance in solubilizing fatty acids under the acidic conditions in the lumen of the upper jejunum of the sheep. Scott $\&$ Lough (I971) found that the addition of bile salts alone to sheep duodenal digesta effected the solubilization of some $30 \%$ of the unesterified fatty acids which were solubilized in the presence of sheep gall-bladder bile at $\mathrm{pH}_{4} \cdot 0$. With regard to the results given in Table 3 it is likely that, as suggested by Scott $\&$ Lough (1971), phospholipid, and in particular phosphatidylethanolamine, originating in the digesta increases the solubilizing effect of bile.

The solubilization of the main fatty acids of post-rumen digesta in micellar solutions of bile salts and phospholipids is only one factor likely to influence the over-all process of lipid absorption in the sheep. Other factors, such as the rate at which the fatty acids are transferred from association with the particulate matter of the digesta to micellar solution and the relative importance of the main amphiphiles of the small intestine in effecting this transfer, are topics which must await further study. However, the influence of the phospholipolysis of lecithin on the micellar 
solubilization of fatty acids in bile salt solution and the physiological implications of such an effect on lipid absorption in the sheep are the subjects of the following paper.

The authors wish to thank Dr G. A. Garton for his helpful criticism of the manuscript and Mrs J. A. Anderson for her technical assistance.

\section{REFERENCES}

Bangham, A. D. (1968). Prog. Biophys. mol. Biol. I8, 29.

Dittmer, J. C. \& Lester, R. L. (1964). F. Lipid Res. 5, 126.

Elving, P. J., Markowitz, J. M. \& Rosenthal, I. (1956). Analyt. Chem. 28, i 179.

Freeman, C. P. (1969). Br. F. Nutr. 23, 249.

Garton, G. A. (1 967). Wld Rev. Nutr. Diet. 7, 225.

Hartley, G. S. (1938). F. chem. Soc. p. 1968.

Heath, T. J. \& Hill, L. N. (1969). Aust. F. biol. Sci. 22, ror 5.

Heath, T. J. \& Morris, B. (1963). Br. F. Nutr. 17, 465.

Hendler, R. W. (1964). Analyt. Biochem. 7, I10.

Hofmann, A. F. (rg63). Biochem. F. 89, 57.

Hofmann, A. F. (1964). In New Biochemical Separations, p. 266 [A. T. James and L. J. Morris, editors]. London: van Nostrand.

Hofmann, A. F. \& Borgström, B. (1962). Fedn Proc. Fedn Am. Socs exp. Biol. 21, 43.

Hofmann, A. F. \& Small, D. M. (1967). A. Rev. Med. 18, 333.

John, L. M. \& McBain, J. W. (1948). F. Am. Oil Chem. Soc. 25, 40.

Kunsman, J, E. (1966). Characterisation of the lipids from pure cultures of rumen bacteria. PhD Thesis, University of Maryland, USA.

Leat, W. M. F. \& Harrison, F. A. (1969). Q. Il exp. Physiol. 54, I87.

Lennox, A. M. \& Garton, G. A. (1968). Br. F. Nutr. 22, 247.

Lennox, A. M., Lough, A. K. \& Garton, G. A. (I 968). Br. F. Nutr. 22, 237.

McBain, J. W. \& Sierichs, W. C. (r948). F. Am. Oil Chem. Soc. 25, 221.

Malins, D. C. \& Mangold, H. K. (r960). Y. Am. Oil Chem. Soc. 37, 576.

Rhodes, D. N. \& Lea, C. H. (1957). Biochem. F. 65, 526.

Rouser, G. (1968). Biochem. Prep. 12, 73.

Savary, P. (1966). Biochim. biophys. Acta 125, 328.

Scott, A. M. \& Lough, A. K. (197 I). Br. F. Nutr. 25, 307.

Small, D. M. (I97I). In The Bile Acids, Chemistry, Physiology and Metabolism, vol. x, p. 249 [D. P. Nair and D. Kritchevsky, editors]. New York: Plenum Publishing Co.

Smith, A., Anderson, L. J. \& Lough, A. K. (1973). Chemy Ind. p. 484.

Smith, A. \& Lough, A. K. (1973). Proc. Nutr. Soc. 32, 62A. 